Bianca de Almeida-Pititto'

Simon J Griffin"

Stephen J Sharp"

Amélia T Hirai"'

Suely G A Gimeno"'

Sandra R G Ferreira'

Departamento de Nutrição em Saúde Pública. Faculdade de Saúde Pública. Universidade de São Paulo (USP). São Paulo, SP, Brasil

Medical Research Council Epidemiology Unit. Cambridge, UK

III Departamento de Medicina Preventiva. Universidade Federal de São Paulo. São Paulo, SP, Brasil

Correspondence:

Bianca de Almeida-Pititto

Faculdade de Saúde Pública - USP

Departamento de Nutrição

Av. Dr. Arnaldo, 715

01246-904 São Paulo, SP, Brasil

E-mail: almeida.bi@uol.com.br

Received: $7 / 18 / 011$

Approved: 1/30/2012

Article available from: www.scielo.br/rsp

\section{A behavioral intervention in a cohort of Japanese-Brazilians at high cardiometabolic risk}

\author{
Intervenção comportamental em \\ nipo-brasileiros com alto risco \\ cardiometabólico
}

\section{ABSTRACT}

OBJECTIVE: To assess the effect of a health promotion program on cardiometabolic risk profile in Japanese-Brazilians.

METHODS: A total of 466 subjects from a study on diabetes prevalence conducted in the city of Bauru, southeastern Brazil, in 2000 completed a 1-year intervention program (2005-2006) based on healthy diet counseling and physical activity. Changes in blood pressure and metabolic parameters in the 2005-2006 period were compared with annual changes in these same variables in the 2000-2005 period.

RESULTS: During the intervention, there were greater annual reductions in mean (SD) waist circumference [-0.5(3.8) vs. $1.2(1.2) \mathrm{cm}$ per year, $\mathrm{p}<0.001]$, systolic blood pressure [-4.6(17.9) vs. 1.8(4.3) $\mathrm{mmHg}$ per year, $\mathrm{p}<0.001$ ], 2-hour plasma glucose [-1.2(2.1) vs. $-0.2(0.6) \mathrm{mmol} / \mathrm{L}$ per year, $\mathrm{p}<0.001]$, LDL-cholesterol $[-0.3(0.9)$ vs. $-0.1(0.2) \mathrm{mmol} / \mathrm{L}$ per year, $\mathrm{p}<0.001]$ and Framingham coronary heart disease risk score $[-0.25(3.03)$ vs. $0.11(0.66)$ per year, $p=0.02]$ but not in triglycerides [0.2(1.6) vs. $0.1(0.42) \mathrm{mmol} / \mathrm{L}$ per year, $\mathrm{p}<0.001]$, and fasting insulin level [1.2(5.8) vs. $-0.7(2.2) \mathrm{IU} / \mathrm{mL}$ per year, $\mathrm{p}<0.001]$ compared with the pre-intervention period. Significant reductions in the prevalence of impaired fasting glucose/impaired glucose tolerance and diabetes were seen during the intervention (from $58.4 \%$ to $35.4 \%, \mathrm{p}<0.001$; and from $30.1 \%$ to $21.7 \%$, $\mathrm{p}=$ 0.004 , respectively).

CONCLUSIONS: A one-year community-based health promotion program brings cardiometabolic benefits in a high-risk population of Japanese-Brazilians.

DESCRIPTORS: Cardiovascular Diseases, prevention \& control. Diabetes Mellitus, Type 2, prevention \& control. Evaluation of the Efficacy-Effectiveness of Interventions. Food and Nutrition Education. Physical Education and Training. Asian Continental Ancestry Group. 


\section{RESUMO}

OBJETIVO: Avaliar o efeito do programa de promoção de saúde no perfil de risco cardiometabólico de nipo-brasileiros.

MÉTODOS: Um total de 466 participantes de estudo de prevalência de diabetes em Bauru, SP, no ano de 2000 completou um programa de intervenção de um ano (2005-2006) baseado em aconselhamento sobre dieta saudável e prática de atividade física. Alterações em pressão arterial e parâmetros metabólicos entre 2005 e 2006 foram comparados com alterações anuais nessas mesmas variáveis entre 2000 e 2005.

RESULTADOS: Durante a intervenção, foram observadas maiores reduções anuais médias (dp) na circunferência da cintura $[-0,5(3,8)$ vs. $1,2(1,2) \mathrm{cm} /$ ano, $\mathrm{p}<0,001]$, pressão arterial sistólica $[-4,6(17,9)$ vs. $1,8(4,3) \mathrm{mmHg} / \mathrm{ano}, \mathrm{p}<$ $0,001]$, glicemia $2 \mathrm{~h}$ pós-sobrecarga de glicose $[-1,2(2,1) \mathrm{vs} .-0,2(0,6) \mathrm{mmol} / \mathrm{L} /$ ano, $\mathrm{p}<0,001]$, LDL-c $[-0,3(0,9)$ vs. $-0,1(0,2) \mathrm{mmol} / \mathrm{L} / \mathrm{ano}, \mathrm{p}<0,001] \mathrm{e}$ escore de Framingham $[-0,25(3,03)$ vs. $0,11(0,66) /$ por ano, $p=0,02]$, mas não em triglicérides $[0,2(1,6)$ vs. $0,1(0,42) \mathrm{mmol} / \mathrm{L} / \mathrm{ano}, \mathrm{p}<0,001]$ e insulinemia de jejum $[1,2(5,8)$ vs. $-0,7(2,2) \mathrm{UI} / \mathrm{mL} / \mathrm{ano}, \mathrm{p}<0,001]$, comparado com o período pré-intervenção. Ocorreram reduções significativas na prevalência de glicemia de jejum alterada e tolerância à glicose diminuída após um ano de intervenção (de 58,4\% para $35,4 \%$, p < 0,001; e de $30,1 \%$ para $21,7 \%, \mathrm{p}=$ 0,004 , respectivamente).

CONCLUSÕES: O programa de intervenção de um ano em hábitos de vida traz benefícios ao perfil de risco cardiometabólico em indivíduos nipo-brasileiros de alto risco.

DESCRITORES: Doenças Cardiovasculares, prevenção \& controle. Diabetes Mellitus Tipo 2, prevenção \& controle. Avaliação de EficáciaEfetividade de Intervenções. Educação Alimentar e Nutricional. Educação Física e Treinamento. Grupo com Ancestrais do Continente Asiático.

\section{INTRODUCTION}

Several trials have confirmed that type 2 diabetes is preventable through intensive lifestyle interventions focusing on diet and physical activity among those with impaired glucose tolerance. ${ }^{8,21}$ Although the reduction in the incidence of diabetes assessed by annual glucose tolerance test was around $58 \%$, the magnitude of changes in cardiovascular risk factors was more modest. Furthermore, glucose tolerance tests are unlikely to be a practical strategy to identify high-risk individuals and intensive lifestyle interventions such as those proposed in diabetes prevention trials are not widely available. The challenge is therefore to translate the findings of diabetes prevention trials into strategies to reduce cardiometabolic risk in the general population. ${ }^{19}$

One of the highest prevalence rates of diabetes worldwide have been reported in Japanese-Brazilians ${ }^{5}$ who also have many other cardiovascular risk factors. ${ }^{16}$ Cardiovascular disease was seen in $14 \%$ of this population ${ }^{20}$ in 2000 . Unhealthy diet and low physical activity have been the culprit risk factors for increasing incidence rates of diabetes in several ethnic groups. ${ }^{7}$ High fat intake was associated with metabolic syndrome among Japanese-Brazilians in cross-sectional and longitudinal studies. ${ }^{3,4}$ The present study aimed to assess the effect of a 1-year community-based health promotion program in a population of JapaneseBrazilians by comparing their cardiometabolic profile before and after the intervention.

\section{METHODS}

Cross-sectional study carried out with subjects from the Study on Diabetes and Associated Diseases in a Population of Japanese-Brazilians conducted in the city of Bauru, southeastern Brazil, in 2000..$^{5}$ A total of 1,330 first- (Japan-born) and second-generation (Brazilborn) Japanese-Brazilians of both genders participated in the previous cross-sectional study and were invited to join a community-based health promotion program commencing in 2005. 


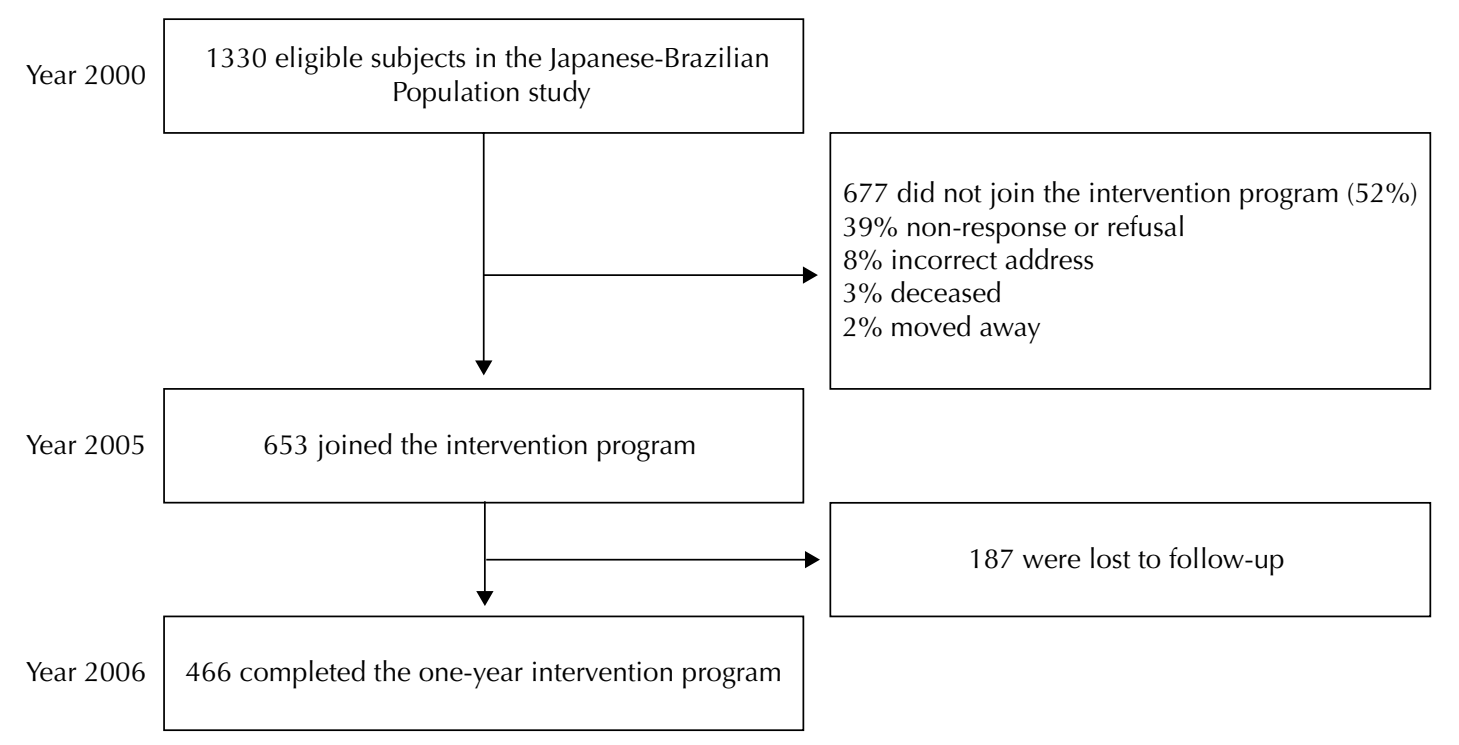

Figure 1. Flowchart of subjects through each stage of the study. City of Bauru, southeastern Brazil, 2000, 2005 and 2006.

The study purposes and potential benefits of the behavioral intervention were outlined in invitation letters and telephone contacts. The 653 subjects who agreed to participate in the study had lower mean (SD) body mass index (BMI) [24.8 (3.7) vs. $25.2(4.2) \mathrm{kg} / \mathrm{m}^{2}, \mathrm{p}<0.05$ ] and higher systolic blood pressure [134.6 (25.6) vs. 130.0 (22.5) $\mathrm{mmHg}, \mathrm{p}<0.05]$ in 2000 compared with non-subjects, but were otherwise similar. One year later, 466 remained in the intervention program and were reevaluated in 2006. Figure 1 illustrates the study design including causes of non-participation. Subjects who were lost to follow-up in 2006 had lower 2-hour plasma glucose levels in 2005 than those who were reevaluated [7.6 (2.9) vs. $8.2(2.9) \mathrm{mmol} / \mathrm{L}, \mathrm{p}<0.02]$, but all other demographic and clinical characteristics were similar.

The results of the 466 subjects who started the intervention in 2005 and remained in the program one year later are presented here.

The health promotion program targeted changes in dietary intake and levels and patterns of physical activity. ${ }^{2}$ It was based on World Health Organization (WHO) recommendation ${ }^{\mathrm{a}}$ and a previous trial conducted among overweight Brazilian adults. ${ }^{17}$ Over a 12 -month period, each subject was offered one individual visit with a nutritionist, one group session on nutrition education, one group session for physical activity counseling, and two community exercise classes including walking, stretching, and dancing. Group sessions included 10 subjects and were coordinated by nutritionists and physical educators. The subjects' relatives were also invited to join the group sessions.
Dietary recommendations consisted of changes in total energy intake according to each individual's nutritional status; a list of food replacements was provided. The target proportions of macronutrients related to total energy intake were $50 \%$ to $60 \%$ of energy intake in carbohydrates; $<30 \%$ in total fat; $<10 \%$ in saturated fat; $10 \%$ to $15 \%$ in proteins; $<300 \mathrm{mg}$ of cholesterol and $15 \mathrm{~g}$ of vegetable fiber. Trained nutritionists monitored diet using 24-hour food recalls. Subjects were encouraged to engage in at least 30 minutes of physical activity per day. Compliance was estimated by the short version of the International Physical Activity Questionnaire. Physical educators and nutritionists reinforced the importance of adopting a healthy lifestyle and discussed the barriers to reaching the goals of the intervention program during the group sessions. Engagement in other physical activities opportunities was recommended. They did not receive any other counseling during the study period. They were instructed to maintain any previous medical treatment. Use of medications was taken into consideration in the statistical analysis.

Subjects underwent laboratory tests following standard multi-professional protocols in an outpatient clinic at baseline and after completing the 12-month intervention program.

Body weight and height were measured using calibrated electronic scales and a fixed rigid stadiometer, respectively, while subjects wore light clothing without shoes. BMI was calculated as weight (kilograms) divided by squared height (meters). Waist circumference was measured with an inextensible tape according to the WHO technique. ${ }^{b}$ Blood pressure was taken three times

a World Health Organization. Food and Agricultural Organization. The scientific basis for diet, nutrition and the prevention of type 2 diabetes. Geneva; 2003.

${ }^{\mathrm{b}}$ World Health Organization. Obesity: preventing and managing the global epidemic. Report of WHO Consultation on Obesity. Geneva; 1998. 
using an automatic device (Omron model HEM-712C, Omron Health Care, Inc, USA) after a 5-minute rest in the sitting position. The mean of the second and third measurements was calculated.

Fasting blood samples were taken and a 75-g oral glucose tolerance test was performed. Samples were immediately centrifuged and analyzed in a local laboratory. Plasma glucose was measured by the glucose-oxidase method and lipoproteins were determined enzymatically with an automatic analyzer. The American Diabetes Association criteria were used to categorize glucose tolerance status as diabetes, impaired fasting glucose (IFG) and impaired glucose tolerance (IGT). ${ }^{1}$ All remaining samples were stored at $-80^{\circ} \mathrm{C}$ prior to hormone assay. Insulin was determined by immunometric assay using a quantitative chemiluminescent kit (Euro DPC Limited - Glyn Rhonwy, Llanberis, Caernarfon, Gwynedd, UK), with analytical sensitivity of $2.0 \mathrm{uIU} / \mathrm{mL}$; intra-assay coefficient of variability ranged from $5.3 \%$ to $6.4 \%$ and the inter-assay coefficient of variability ranged from $5.9 \%$ to $8.0 \%$. Insulin secretion was determined according to the homeostasis model assessment [HOMA- $\beta=20 \times$ fasting insulin $(\mu \mathrm{U} / \mathrm{mL}) /$ fasting glucose $(\mathrm{mmol} / \mathrm{L})-$ $3.5] .{ }^{13}$ The cardiovascular risk score was based on equations derived from the US Framingham cohort study. ${ }^{6}$

The prevalence of IFG/IGT and diabetes in 2000, 2005 and 2006 were compared by the chi-square test. For each anthropometric and metabolic characteristic the mean and SD were calculated in 2000, 2005 and 2006. The annual change of each parameter from 2000 to 2005 (calculated by subtracting the mean in 2000 from that in 2005 and dividing by 5) and from 2005 to 2006 were calculated and presented as mean and $95 \%$ confidence interval $(95 \% \mathrm{CI})$. These differences from 2005 to 2006 were standardized and are shown in Figure 2. To compare magnitudes of changes between pre- and post-intervention, the differences in variable

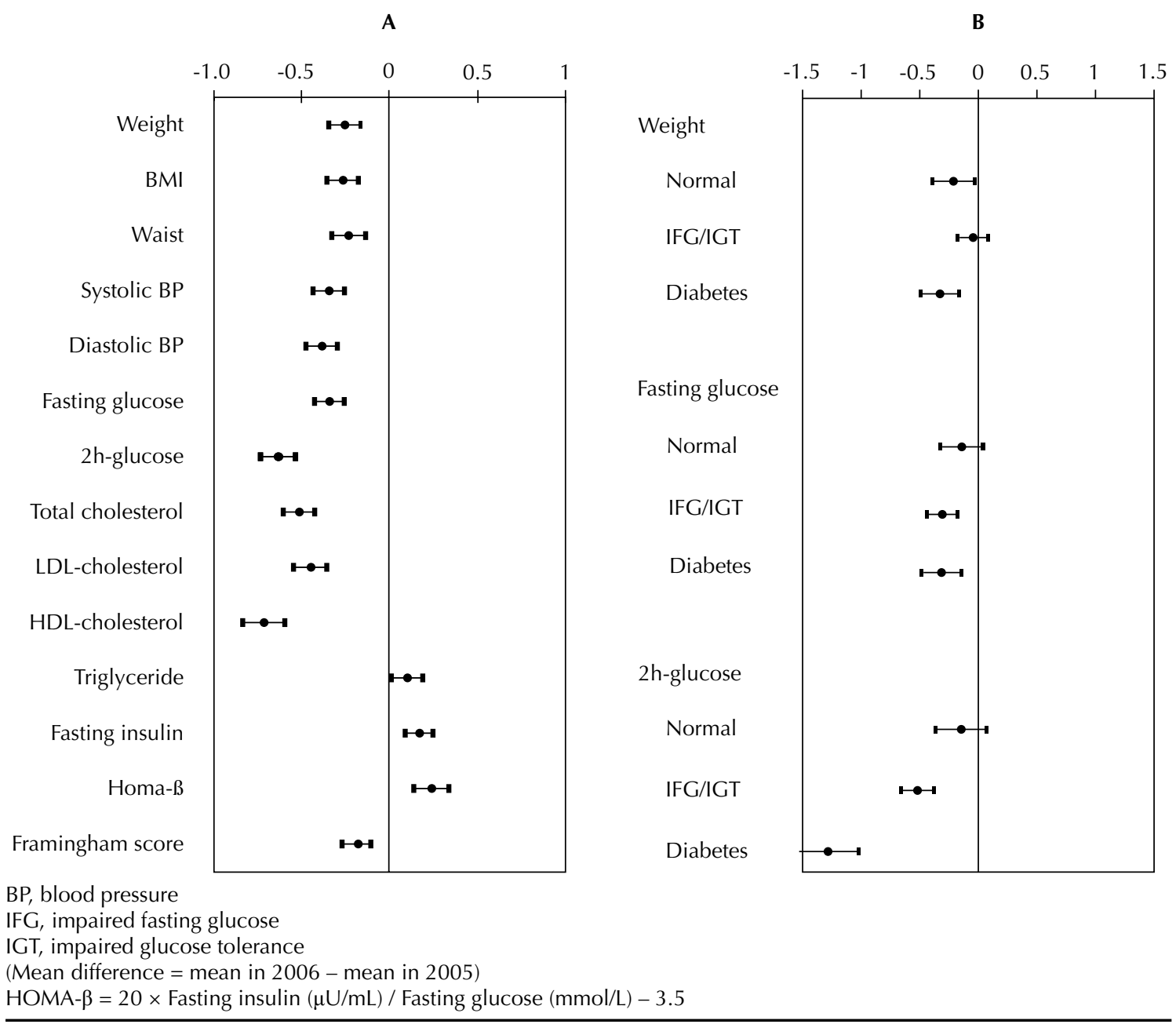

Figure 2. Standardized differences (and related 95\% confidence interval) of anthropometric and metabolic variables between 2005 and 2006 (panel A) and standardized differences in weight, fasting and 2-hour plasma glucose stratified by glucose tolerance status in 2005 (panel B). City of Bauru, southeastern Brazil, 2005 and 2006. 
changes obtained in these two periods were calculated ( $\Delta$ difference $=$ change from 2005 to 2006 - annual change from 2000 to 2005). These differences between annual change in the intervention (2005-2006) and pre-intervention period (2000-2005) and 95\% CI were reported alongside standardized versions of these differences to allow comparisons between different characteristics.

The differences in annual change were also estimated after stratification by age ( $<60$ and $\geq 60$ years old), generation (first- and second-generation), gender and glucose tolerance status. Sensitivity analyses were conducted according to self-reported consumption of alcohol and use and/or change of medication (antihypertensives, lipid lowering and antidiabetic agents) that might influence outcomes.

All statistical analyses were performed using SPSS 12.0.

The Research Ethics Committee approved the study protocol (Protocol 1710, Of.COEP/151/08) and a written consent was obtained from all subjects.

\section{RESULTS}

The 466 subjects had a mean age of 55.3 years in 2000 ; $53.0 \%$ were women and $79.4 \%$ were second-generation Japanese-Brazilians.

The prevalence of IFG/IGT was stable from 2000 to 2005 (58.8\% and $58.4 \%$, respectively) but significantly feel during the intervention $\left(35.4 \%, \chi^{2}=49.3, p<0.001\right)$.
The prevalence of diabetes declined from 2000 to 2005 (from $37.3 \%$ to $30.1 \%, \mathrm{p}=0.001$ ) and further decreased during the intervention (from $30.1 \%$ to $21.7 \%, \chi^{2}=$ $8.51, \mathrm{p}=0.004$ ).

Between 2000 and 2005 subjects showed increased mean weight, waist circumference, systolic and diastolic blood pressure and Framingham cardiovascular risk score and small reductions in triglycerides, fasting and 2-hour plasma glucose, total, LDL and HDL-cholesterol levels, insulin and HOMA- $\beta$ levels (Table). Between 2005 and 2006, there were reductions in waist circumference, systolic and diastolic blood pressure, fasting and 2-hour plasma glucose, total, LDL and HDL-cholesterol levels, and Framingham cardiovascular risk score, and increases in triglyceride and fasting insulin levels and HOMA- $\beta$. There was a reduction in the Framingham cardiovascular risk score during the one-year intervention period $[0.11(0.66)$ vs. -0.25 (3.03) per year, $\mathrm{p}=0.02]$, following an annual increase from 2000 to 2005.

The changes in variables between 2005 and 2006 were standardized (Figure 2, panel A). Subjects with abnormal glucose metabolism (IFG, IGT or diabetes) in 2005 showed greater decreases in fasting and 2-hour plasma glucose following the intervention than those with normal glucose tolerance. Those with diabetes had the greatest weight loss (Figure 2, panel B).

There were significantly greater improvements in the majority of cardiovascular risk factors post-intervention compared to the pre-intervention period, except for

Table. Mean values (and standard deviation) for anthropometric and metabolic variables at the three stages of the study and annual differences (95\% confidence interval) in the pre- and post-intervention periods. City of Bauru, southeastern Brazil, 2000, 2005 and 2006. $(\mathrm{N}=466)$

\begin{tabular}{|c|c|c|c|c|c|}
\hline Variable & 2000 & 2005 & 2006 & $\begin{array}{l}\text { Annual difference } \\
\text { (2000 to 2005) }\end{array}$ & $\begin{array}{l}\text { Annual difference } \\
\text { (2005 to 2006) }\end{array}$ \\
\hline Weight (kg) & $61.5(12.4)$ & $61.6(12.4)$ & $61.2(12.7)$ & $-0.01(-0.1$ to 0.05$)$ & $-0.4(-0.6$ to -0.2$)$ \\
\hline Body mass index $\left(\mathrm{kg} / \mathrm{m}^{2}\right)$ & $24.8(3.7)$ & $24.9(4.1)$ & $24.7(4.1)$ & $-0.07(-0.1$ to -0.04$)$ & $-0.2(-0.3$ to -0.1$)$ \\
\hline Waist circumference $(\mathrm{cm})$ & $84.0(10.1)$ & $88.5(10.4)$ & $88.1(10.6)$ & $1.2(1.0$ to 1.3$)$ & $-0.5(-0.9$ to -0.2$)$ \\
\hline Systolic blood pressure (mm Hg) & $134.6(25.6)$ & $139.3(21.8)$ & $134.3(21.4)$ & $1.8(1.4$ to 2.2$)$ & $-4.6(-6.3$ to -3.0$)$ \\
\hline Diastolic blood pressure $(\mathrm{mm} \mathrm{Hg})$ & $78.1(13.9)$ & $81.2(12.0)$ & $78.4(11.6)$ & $0.6(0.4$ to 0.8$)$ & $-2.9(-3.7$ to -1.9$)$ \\
\hline Fasting plasma glucose $(\mathrm{mmol} / \mathrm{L})$ & $6.9(1.7)$ & $6.2(1.7)$ & $5.8(1.5)$ & $-0.2(-0.2$ to -0.1$)$ & $-0.4(-0.5$ to -0.2$)$ \\
\hline 2-hour plasma glucose $(\mathrm{mmol} / \mathrm{L})$ & $9.2(4.39)$ & $8.3(2.9)$ & $7.2(2.5)$ & $-0.2(-0.3$ to -0.2$)$ & $-1.2(-1.4$ to -0.9$)$ \\
\hline Total cholesterol $(\mathrm{mmol} / \mathrm{L})$ & $5.6(1.1)$ & $5.5(1.1)$ & $5.1(1.0)$ & $-0.1(-0.1$ to -0.05$)$ & $-0.4(-0.5$ to -0.1$)$ \\
\hline LDL-cholesterol (mmol/L) & $3.3(0.9)$ & $3.3(1.0)$ & $3.0(0.8)$ & $-0.1(-0.1$ to -0.05$)$ & $-0.3(-0.4$ to -0.2$)$ \\
\hline HDL-cholesterol (mmol/L) & $1.3(0.3)$ & $1.4(0.3)$ & $1.3(0.3)$ & $0.01(-0.01$ to -0.002$)$ & $-0.1(-0.2$ to -0.1$)$ \\
\hline Triglycerides (mmol/L) & $2.6(2.3)$ & $1.8(1.4)$ & $2.0(1.6)$ & 0.1 (0.1 to 0.07$)$ & $0.2(0.04$ to 0.2$)$ \\
\hline Fasting insulin (IU/mL) & $9.4(4.4)$ & $5.9(9.5)$ & $7.6(11.8)$ & $-0.7(-0.9$ to -0.5$)$ & $1.2(0.7$ to 1.8$)$ \\
\hline НОМА- $\beta$ & $24.1(30.4)$ & $15.8(30.0)$ & $22.6(37.9)$ & $-1.5(-2.2$ to -0.8$)$ & $6.2(3.7$ to 8.6$)$ \\
\hline $\begin{array}{l}\text { Framingham coronary heart } \\
\text { disease risk score }\end{array}$ & $7.2(5.4)$ & $7.8(4.7)$ & $7.6(4.3)$ & $0.1(0.05$ to 0.2$)$ & $-0.2(-0.5$ to -0.02$)$ \\
\hline
\end{tabular}

Homeostasis model assessment $(\mathrm{HOMA}-\beta)=20 \times$ fasting insulin $(\mu \mathrm{U} / \mathrm{mL}) /$ fasting glucose $(\mathrm{mmol} / \mathrm{L})-3.5$ 
HDL-cholesterol, triglycerides, and fasting insulin (Figure 3).

The magnitude, direction and statistical significance of the results were unchanged when stratified by gender, generation and age (data not shown). They were also unaffected when stratified by prescribed medication and self-reported alcohol consumption (data not shown).

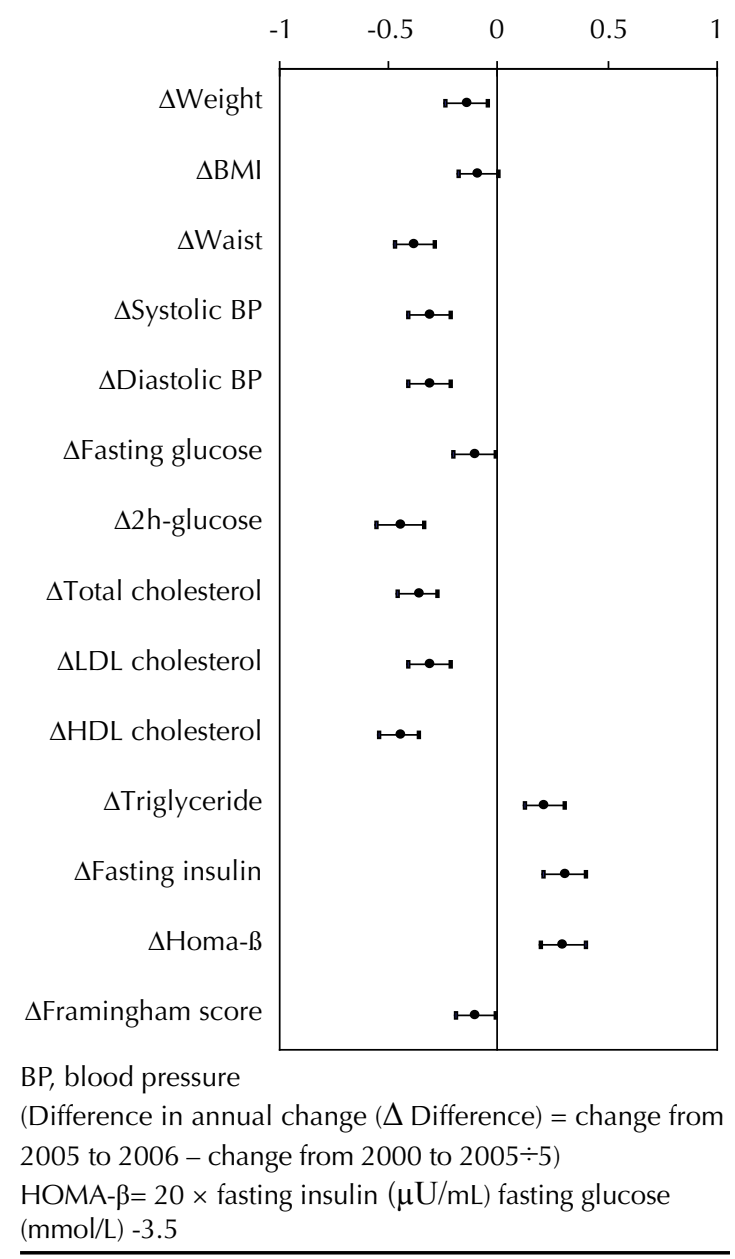

Figure 3. Standardized differences (and related 95\% confidence interval) of annual changes in variables. City of Bauru, southeastern Brazil, 2000-2005 and 2005-2006.

\section{DISCUSSION}

This community-based study suggests that a relatively simple health promotion program including lifestyle changes counseling was associated with improved cardiovascular risk factors, modeled cardiovascular risk and glucose tolerance, and a reduction in the prevalence of diabetes in a high-risk population. Our findings support the potential for lifestyle change in diabetes and cardiovascular disease prevention and are broadly consistent with results from previous studies of more intensive behavioral interventions among people with impaired glucose tolerance. ${ }^{8,21}$ A particular strength of our approach was the relatively low cost, both for identification of high-risk individuals and the intervention, making it convenient in countries with limited resources for health.

In 2005 the study subjects were overweight and had a high waist circumference ${ }^{\mathrm{c}}$ considering their overall mean BMI $\left(24.7 \mathrm{~kg} / \mathrm{m}^{2}\right)$. Although the reductions in anthropometric parameters during the intervention were modest, statistically significant and clinically relevant reductions were observed for blood pressure, plasma glucose, glucose tolerance, and total and LDL-cholesterol levels among those who enrolled in the community program. Similar findings were reported in diabetes prevention studies among people with IGT. The Da Qing Study, Finnish Diabetes Prevention Study (DPS), and Diabetes Prevention Program showed that diabetes could be prevented by sustained lifestyle changes associated with modest weight loss. ${ }^{8,14,21}$ In the Indian Diabetes Prevention Program, there was a $26.4 \%$ reduction in the relative risk of progression to diabetes with almost no change in weight and waist circumference. ${ }^{15}$ An intensive lifestyle intervention among Japanese men was associated with a reduction in the incidence of diabetes greater than might be expected with a reduction in $\mathrm{BMI},{ }^{10}$ suggesting that while weight loss may be desirable, it does not fully explain the effects of behavioral interventions. Longer follow-up of the Japanese-Brazilian subjects will provide more input concerning the potential for sustained effects on the risk of diabetes and persistence of cardiometabolic benefits.

A limitation of this study is that no control group was used for comparison during the intervention. Hence there is a possibility that the positive findings may be due to confounding, regression to the mean or selection bias. The difference in changes in risk factors over the 5-year pre-intervention period compared with the 1-year intervention period does not rule out these potential explanations but does make them less likely. Data from this same population in the pre-intervention period works as a historical control, which means that this study used a plausibility design. ${ }^{22}$ This type of study is a feasible option for large scale interventions and provides valid evidence of impact. ${ }^{22}$ As for regression to the mean, if any, it would be similar in both periods studied. Since confounding factors that could produce these benefits on cardiometabolic profile were not identified, the results should be attributed to intervention

${ }^{c}$ World Health Organization. WHO 2000. Steering Committee of the Western Pacific Region of the WHO, the International Association for the Study of Obesity Task Force. The Asia-Pacific perspective: redefining obesity and its treatment. Geneva; 2000. 
effects. Although around half of those invited agreed to take part in the health promotion program, the characteristics of subjects and non-subjects were broadly similar, also suggesting that selection bias is not likely. There was no allocation concealment that increases the likelihood of bias in the outcome assessment. However, it is unlikely to affect laboratory tests and all study measures were taken according to standard operating procedures, and blood pressure was measured using automated equipment. The sensitivity analysis also suggests that the findings are not due to changes in prescribed medication over time. The follow-up rate was reasonably good $(71 \%)$. Those with missing data in 2006 were similar to those who underwent reevaluation except that they showed lower 2-hour plasma glucose levels. If subjects who were lost to follow-up had more severe risk factors then the benefits associated with the community program would be overestimated. Although we may have underestimated the differences in annual change in risk factors between 2000 to 2005 and 2005 to 2006 as the first period of observation was about more than five times as long as the second one.

The effects of the health promotion program were not modified by age, gender or generation; however, those with abnormal glucose metabolism in 2005 had greater decreases in plasma glucose during the intervention than those with normal glucose tolerance. The unexpected decrease in HDL-cholesterol (albeit remaining within the normal range) and increase in triglyceride levels persisted after sensitivity analyses. The changes in physical activity may not have been strong enough to induce an increase in HDL-cholesterol levels. Given the harmful effect of fat intake on cardiometabolic profile in this population, as previously shown by our group, ${ }^{3,4}$ the study dietary counseling strongly advocated a reduction in food consumption rich in fat. This could have resulted in a relative increase in carbohydrate intake which might have contributed to increased triglyceride levels. ${ }^{18}$ Analyses of self-reported physical activity and diet data may help better understand these findings and possible mechanisms by which the intervention program appears to have produced beneficial effects. Fasting insulin levels increased post-intervention. As the HOMA- $\beta$ was also higher after the intervention, it is possible that lifestyle changes were associated with improved beta cell function which was also reflected in the beneficial changes in metabolic parameters.

We do not know whether other discrete high-risk population subgroups would have the same uptake of, or response to, a health promotion program as seen among Japanese descendants. The benefits of the present program cannot be extrapolated to the entire Brazilian population or Asian immigrants living in other countries. We also cannot assure these changes will be sustained. Albeit more pronounced than in this study, evidence from the Finnish DPS shows that the benefits of behavioral interventions can persist following cessation of the intervention. ${ }^{12}$ It contrasts with the effect of risk reduction associated with the use of antidiabetic drugs which ceases when the medication is discontinued. ${ }^{9}$ It is also unclear whether improvements in proximal risk factors will translate into reductions in unfavorable health outcomes, although recent data from the long-term follow-up of the Da Qing Study looks promising. ${ }^{11}$ Follow-up of Japanese-Brazilian subjects may clarify whether changes in cardiometabolic risk factors will translate into the prevention of cardiovascular events. Furthermore, lifestyle changes which probably accounted for the observed improvements in risk factors might also be associated with reduced risk of other adverse health outcomes such as osteoporosis and some cancers.

A simple community-based behavioral counseling program over one year improved the cardiometabolic profile in a high-risk population of Japanese-Brazilians. Obesity, diabetes, and their complications pose major public health challenges demanding responses at the population and individual level. Our findings should encourage health care providers to promote a healthy diet and a physically active lifestyle among high-risk individuals and population subgroups.

\section{REFERENCES}

1. American Diabetes Association. Position Statements. Screening for Type 2 Diabetes. Diabetes Care. 2003;26(Suppl 1):S21-4.

DOI:10.2337/diacare.26.2007.S21

2. Ferreira SRG, Gimeno SGA, Hirai AT, Harima $H$, Matsumara L, Pititto BA. Effects of an intervention in eating habits and physical activity in Japanese Brazilian women with a high prevalence of metabolic syndrome. Cad Saude Publica. 2008;24(S2):294-302. DOI:10.1590/S0102-311X2008001400014

3. Freire RD, Castro TG, Cardoso MA, Gimeno SGA, Ferreira SRG. Dietary intakes associated with

metabolic syndrome in a cohort of Japanese ancestry. Br J Nutr. 2006;96(3):532-8.

4. Freire RD, Shinzato AR, Cardoso MA, Ferreira SRG, Japanese-Brazilian Diabetes Study Group. Dietary fat is associated with metabolic syndrome in JapaneseBrazilians. Diabetes Care. 2005;28(7):1779-85. DOI:10.2337/diacare.28.7.1779

5. Gimeno SGA, Ferreira SRG, Franco LJ, Hirai A, Matsumura L, Moisés RCS, et al. Prevalence and 7-year incidence of type 2 diabetes mellitus in a JapaneseBrazilian population: an alarming public health problem. Diabetologia. 2002;45(12):1635-8. DOI:10.1007/s00125-002-0963-x 
6. Gordon T, Kannel WB. Multiple risk functions for predicting coronary heart disease: the concept, accuracy, and application. Am Heart J. 2002;103(6):1031-9. DOI:10.1016/0002-8703(82)90567-1

7. Kanazawa M, Yoshiike N, Osaka T, Numba Y, Zimmet $P$, Inoue $S$. Criteria and classification of obesity in Japan and Asia-Oceania. World Rev Nutr Diet. 2005;94:1-12. DOI:10.1046/j.1440-6047.11.s8.19.x

8. Knowler WC, Barrett-Connor E, Fowler SE, Hamman RF, Lachin JM, Walker EA, et al. The Diabetes Prevention Program: reduction in the incidence of type 2 diabetes with lifestyle intervention or metformin. $N$ Engl J Med. 2002;346(6):393-403.

DOI: 10.1056/NEJMoa012512

9. Knowler WC, Hamman RF, Edelstein SL, BarrettConnor E, Ehrmann DA, Walker EA, et al. Prevention of type 2 diabetes with troglitazone in the Diabetes Prevention Program. Diabetes. 2005;54(4):1150-6. DOI:10.2337/diabetes.54.4.1150

10. Kosaka K, Noda M, Kuzuya T. Prevention of type 2 diabetes by lifestyle intervention: a Japanese trial in IGT males. Diabetes Res Clin Pract. 2005; 67(2):152-62. DOI:10.1016/j.diabres.2004.06.010

11. Li G, Zhang P, Wang J, Gregg EW, Yang W, Gong Q, et al. The long-term effect of lifestyle interventions to prevent diabetes in the China Da Qing Diabetes Prevention Study: a 20-year follow-up study. Lancet. 2008;371(9626):1783-9. DOI:10.1016/S0140-6736(08)60766-7

12. Lindstrom J, Ilanne-Parikka P, Peltonen $M$, Aunola $S$, Eriksson JG, Hemio K, et al. Sustained reduction in the incidence of type 2 diabetes by lifestyle intervention: follow-up of the Finnish Diabetes Prevention Study. Lancet. 2006;368(9548):1673-9.

13. Matthews DR, Hosker JP, Rudenski AS, Naylor BA, Treacher DF, Turner RC. Homeostasis model assessment: insulin resistance and B-cell function from fasting plasma glucose and insulin concentrations in man. Diabetologia. 1985;28(7):412-9. DOI:10.1007/BF00280883

14. Pan XR, Li GW, Hu UH. Effect of diet and exercise in preventing DM type 2 in people with impaired glucose tolerance. The Da Qing IGT and Diabetes Study. Diabetes Care. 1997;20(4):537-54. DOI:10.2337/diacare.20.4.537
15. Ramachandran A, Snehalatha C, Mary S, Mukesh B, Bhaskar AD, Vijay V. The Indian Diabetes Prevention Programme shows that lifestyle modification and metformin prevent type 2 diabetes in Asian Indian subjects with impaired glucose tolerance (IDPP-1). Diabetologia. 2006;49(2):289-97. DOI:10.1007/s00125-005-0097-z

16. Rosenbaum P, Gimeno SGA, Sanudo A, Franco LJ, Ferreira SRG, Japanese-Brazilian Diabetes Study Group. Analysis of criteria for metabolic syndrome in a population-based study of Japanese-Brazilians. Diabetes Obes Metab. 2005;7(4):352-9. DOI:10.1111/j.1463-1326.2004.00402.x

17. Sartorelli DS, Sciarra EC, Franco LJ, Cardoso MA. Primary prevention of type 2 diabetes through nutritional counselling. Diabetes Care. 2004;27(12):3019. DOI:10.2337/diacare.27.12.3019

18. Shai I, Schwarzfuchs D, Henkin Y, Shahar DR, Witkow $S$, Greenberg I, et al. Weight Loss with a LowCarbohydrate, Mediterranean, or Low-Fat Diet. N Engl J Med. 2008;359(3):229-41. DOI:10.1056/NEJMoa0708681

19. Simmons RK, Griffin SJ, Wareham NJ. Researching how to realise the potential of diabetes prevention. Diabet Med. 2007;24(10):1055-7. DOI:10.1111/j.1464-5491.2007.02260.x

20. Siqueira AAF, Franco LJ, Gimeno SGA, Matsumura LK, Barros Jr N, Ferreira SRG. Macrovascular disease in a Japanese-Brazilian population of high prevalence of metabolic syndrome: associations with classical and non-classical risk factors. Atherosclerosis. 2007;195(1):160-6. DOI:10.1016/j.atherosclerosis.2006.09.012

21. Tuomilehto J, Lindstrom J, Eriksson JG, Valle TT, Hamalainen $\mathrm{H}$, Ilanne-Parikka $\mathrm{P}$, et al. Prevention of Type 2 diabetes mellitus by changes in lifestyle among subjects with impaired glucose tolerance. N Eng/ J Med. 2001;344(18):1343-50. DOI:10.1056/NEJM200105033441801

22. Victora CG, Habicht JP, Bryce J. Evidence-based public health: moving beyond randomized trials. Am J Public Health. 2004;94(3):400-5.

DOI:10.2105/AJPH.94.3.400

Paper based on the doctorate thesis by Pititto BA presented to Departamento de Nutrição, Faculdade de Saúde Pública, Universidade de São Paulo, in 2009

Research supported by Conselho Nacional de Desenvolvimento Científico e Tecnológico (CNPq) (505845/2004-0) and Fundação de Amparo à Pesquisa do Estado de São Paulo (FAPESP) (05/50178-7).

The authors declare no conflicts of interest. 